\title{
Material Removal in Ultrasonic Abrasive Polishing of Additive Manufactured Components
}

\author{
Jingsi Wang ${ }^{1, *}$, Jiaqi Zhu ${ }^{1}$ and Pay Jun Liew ${ }^{2}$ \\ 1 Marine Engineering College, Dalian Maritime University, 1 Linghai Road, Ganjingzi District, \\ Dalian 116026, China; lunjizhujiaqi@dlmu.edu.cn \\ 2 Fakulti Kejuruteraan Pembuatan, Universiti Teknikal Malaysia Melaka, Hang Tuah Jaya, \\ Durian Tunggal 76100, Melaka, Malaysia; payjun@utem.edu.my \\ * Correspondence: wjs@dlmu.edu.cn or jixiewangjingsi@hotmail.com; Tel.: +86-139-0408-3642
}

Received: 9 November 2019; Accepted: 6 December 2019; Published: 8 December 2019

check for updates

Featured Application: The study of the material removal mechanisms in ultrasonic abrasive polishing provides technical support for the surface modification of metal-based additive manufactured components which have poor surface quality. In addition, the technology can be further applied to smoothing various complex shapes and the internal features of both metal and non-metal parts, due to the use of loose abrasive particles and the possibility of uniform material removal process.

\begin{abstract}
Powder-based layered Additive Manufacturing (AM) techniques lead to high surface roughness, due to the balling and partial melting of powders, which cannot satisfy the requirements of design and practical use. Consequently, until there is a significant step-change in the resolution of AM technology, finishing processes will be a necessary step in the additive manufacturing process. In this work, ultrasonic abrasive polishing experiments are conducted with the aim of improving the surface quality of additive manufactured components. The roles of cavitation bubbles and abrasive particles in material removal are discussed. The impact action of abrasive particles is simulated using the Smoothed Particle Hydrodynamics (SPH) method. The effects of ultrasonic output power and the concentration of abrasive suspension on machining characteristics are also examined. It is found that the cavitation bubble collapse in ultrasonic polishing can remove the partially melted structures efficiently, and further roughness improvement could be obtained using the micro-cut and impact of abrasive particles in the slurry. An increase in the ultrasonic output power and abrasive concentration within a certain range lead to a more desirable polishing effect.
\end{abstract}

Keywords: ultrasonic abrasive polishing; additive manufacturing; smoothed particle hydrodynamics; cavitation; abrasive

\section{Introduction}

Additive Manufacturing (AM) technology has developed rapidly over the past two decades. Metal-based AM techniques represented by Powder Bed Fusion (PBF) have advantages, including the production of fine features with great geometrical accuracy and high-strength-to-weight ratios. However, its forming mechanism, based on the melting of metal powders, induces the agglomeration of partially melted powders and a balling phenomenon in the process [1]. Therefore, the average roughness $(\mathrm{Ra})$ of metal-based AM parts is generally higher than $10 \mu \mathrm{m}$ [2], which not only affects the appearance, but also greatly influences several functional properties, including fatigue resistance, friction performance and heat transfer [3-5]. Accordingly, post-process finishing is required to improve the surface quality of AM parts [6,7]. 
AM parts always have complex shapes and features, which makes the finishing process difficult. Several surface modification processes for AM parts have been reported in the literature. However, each process has limitations and complexities. Implementing hand polishing as one of the main finishing processes for AM parts would increase the labor cost and time, and the surface quality would be poor. Laser polishing, chemical polishing, electrochemical polishing, and abrasive flow polishing have shown great potential for the treatment of the surfaces of AM parts. Laser polishing is efficient and can directly use the laser source of laser melting deposition equipment, but this technique is prone to causing thermal damage [8] and is more difficult to irradiate with uniform intensity on complex surfaces, which leads to deviations from the designed geometry [9]. Chemical polishing and electrochemical polishing can effectively treat all kinds of freeform surfaces, lattices and porous structural parts $[10,11]$, but do not solve the environment, health and safety problems. In addition, the electric field is limited inside deep cavities in electrochemical polishing, and therefore the internal finishing may be not uniform [11,12]. Abrasive flow machining is an effective process of polishing metal-based AM parts with complex internal cavity and channel structures [7]. However, this method needs to design and control the flow channel for a specific target part, and problems such as the embedding of abrasives and the edge/corner rounding of the parts must be solved [13,14]. Therefore, it is important to exploit new solutions for AM part polishing whilst considering how to maintain the satisfactory geometry and application of the parts.

The mechanical effects of ultrasonic power have been widely used in the removal of materials, such as in UltraSonic Machining (USM) technology. A large number of studies have reported the attractive processing capability of USM for fabricating complex shapes, deep holes, and high-aspect-ratio micro-structures on hard and brittle materials [15-17]. In the USM process, an ultrasonically vibrated tool is used in conjunction with a liquid slurry for material removal. A large number of micro-sized abrasive particles suspended in the slurry flow through the working area and hammer the workpiece repeatedly by the propulsion of the vibrated tool. This induces countless, tiny brittle fractures and removes the material. Despite this, it is reported that USM can also work on the surface in a ductile removal mode, and form tiny machining marks through bubble cavitation and the micro-cut/impact of the abrasive particles $[18,19]$. Therefore, USM has great potential for use in polishing processes which require no material removal, or only very little material removal.

In this study, the ultrasonic abrasive polishing process is proposed to improve the surface quality of metal-based AM parts, which is based on the USM principle and has several advantages including its low cost, ease of operation, and absence of thermal or chemical damages. The cavitation effect in this process is reported as being effective for removing partially melted powders on the surfaces of AM parts [4]. In addition, loose abrasive particles in the slurry can reach any intricate surface, which is more suitable for the polishing of geometrical freedom AM components.

This work aims to explore the machining capability of ultrasonic abrasive polishing in smoothing metal-based AM components. Experiments are conducted to improve the surface quality of SLM-built Inconel 625 specimens using a high-power ultrasonic generator. Silicon carbide mixed with water is used as the slurry. The impact action of the abrasive particles is simulated using the Smoothed Particle Hydrodynamics (SPH) method. The roles of cavitation bubble collapse and the impact of abrasive particles in the polishing process are discussed. The effects of important processing parameters, including ultrasonic output power and concentration of abrasive suspension on machining characteristics, are examined.

\section{Materials and Methods}

\subsection{Materials}

The slurry used in this study was a mixture of silicon carbide particles (particle mean size: $9 \mu \mathrm{m}$ ) and water. The target Inconel 625 specimen was manufactured by a SLM equipment (FARSOON, Changsha, China) with a scanning speed of $7.6 \mathrm{~m} / \mathrm{s}$. The metal powder size ranged from 15 to $53 \mu \mathrm{m}$. 
The powder bed depth was $0.1 \mathrm{~mm}$, and the build orientation is illustrated in Figure 1 . The four side surfaces are the target finishing surfaces.

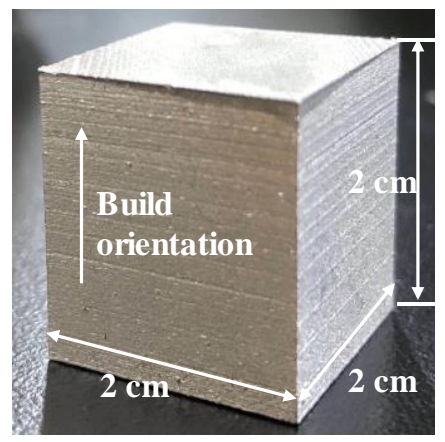

Figure 1. Selective laser melting built specimen.

\subsection{Experimental Setup}

A high-power ultrasonic generator with a frequency range of $20 \sim 25 \mathrm{kHz}$ (SCIENTZ-950E, Ningbo Scientz Biotechnology, Ningbo, China) was used in this work. The diameter of the horn tip was $6 \mathrm{~mm}$. The ultrasonic amplitude could be adjusted purposely by changing the output power, which ranged $5 \sim 600 \mathrm{~W}$. The specimens were fixed and immersed in a container filled with abrasive slurry. The container was surrounded by cold water to prevent a drastic increase in temperature. Figure 2 shows the real illustration of the configuration for the ultrasonic abrasive polishing experiments.

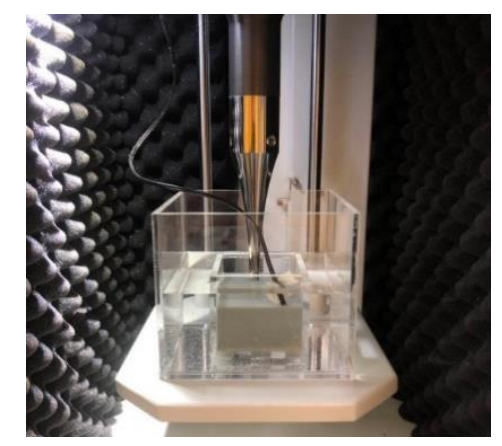

Figure 2. Ultrasonic abrasive polishing setup.

\subsection{Experimental Procedure and Conditions}

Three groups of experiments were conducted, and the detailed conditions are labeled Group 1-3, as shown in Table 1 . To verify the roles of cavitation bubbles and abrasive particles in the finishing process, comparison experiments were conducted with abrasive concentrations of $0 \%$ and $10 \%$, as listed in Group 1. In the case of $0 \%$ (no abrasive particles), cavitation only occurred for material removal. While for $10 \%$, the clearance of 1 and $2 \mathrm{~mm}$ between the horn tip and the workpiece was used for a comparison, and the surface after machining for 5, 10, 20 and 30 min was observed under a scanning electron microscope (TESCAN, Kohoutovice, Czech Republic). Comparison experiments were then carried out with different ultrasonic output powers and abrasive concentrations, as listed in Groups 2 and 3. A laser scanning confocal microscope (LEXT OLS4000, Olympus) was used for the imaging and 3D measurement of the representative surfaces in this study. Roughness measurements were taken with a non-contact laser probe profilometer (NH-3SP, MitakaKouki). For each sample, due to the high standard deviations of AM surface, 5 measurements were utilized to calculate the average Ra value and the standard deviation. For all the experiments, the workpieces were cleaned in an ultrasonic cleaner for $20 \mathrm{~min}$ to remove the abrasive particles and delaminated base materials left on the surface before the observation and measurement. 
Table 1. Experimental conditions.

\begin{tabular}{cccc}
\hline $\begin{array}{c}\text { Ultrasonic Output } \\
\text { Power [W] }\end{array}$ & $\begin{array}{c}\text { Concentration of } \\
\text { Abrasive Suspension }\end{array}$ & $\begin{array}{c}\text { Machining } \\
\text { Time [min] }\end{array}$ & $\begin{array}{c}\text { Clearance Between the Horn Tip } \\
\text { and Workpiece [mm] }\end{array}$ \\
\hline Group 1 & $0 \%$ & 30 & 1 \\
500 & $10 \%$ & $5,10,20,30$ & 1,2 \\
\hline Group 2 & & 1 \\
\hline $400,500,600$ & $10 \%$ & 20 & 1 \\
\hline Group 3 & & \\
\hline 500 & $5,10,20,30,40 \%$ & 20 & \\
\hline
\end{tabular}

\subsection{Simulation Procedure}

\subsubsection{Material Modeling}

To compare the experimental results, the same abrasive material (Silicon carbide) and workpiece material (Inconel 625) were utilized in the simulations. The Mie-Grüneisen Equation of state [20] was employed to describe the initial elastic response of the materials. The strength and damage behavior of silicon carbide was modeled with the Johnson-Holmquist material model [21]. The Johnson-Cook model was employed to model the strength behavior of Inconel 625 [22]. In the Johnson-Cook model [23], the von Mises stress, $\sigma$, is expressed as

$$
\sigma=\left[A+B \varepsilon^{t}\right]\left[1+C \ln \dot{\varepsilon}^{*}\right]\left[1-T^{* m}\right]
$$

where $\varepsilon$ is the equivalent plastic strain, $\dot{\varepsilon}^{*}=\dot{\varepsilon} / \dot{\varepsilon}_{0}$ is the dimensionless plastic strain rate for $\dot{\varepsilon}_{0}=$ $1.0 \mathrm{~s}^{-1}$, and $T^{*}$ is the homologous temperature where $T^{*}=\left(T-T_{\text {room }}\right) /\left(T_{\text {melt }}-T_{\text {room }}\right)$. The five material constants are $A, B, t, C$, and $m$, where $A$ is the yield stress, $B$ and $t$ represent the effects of strain hardening, and $C$ is the strain rate constant. The expression in the first set of brackets gives the stress as a function of strain for $\dot{\varepsilon}^{*}=1.0$ and $T^{*}=0$. The expressions in the second and third set of brackets represent the effects of strain rate and temperature, respectively.

The important parameters for simulations are summarized in Table 2.

Table 2. Material models and important parameters for simulations.

\begin{tabular}{ccc}
\hline Item & SiC & Inconel 625 \\
\hline Equation of state & Polynomial & Linear \\
Density g/cm ${ }^{3}$ & 3.215 & 8.44 \\
Bulk modulus GPa & 220 & 155.8 \\
Strength & Johnson-Holmquist & Johnson-Cook \\
Shear modulus GPa & 193.5 & 81.2 \\
Hugoniot elastic limit GPa & 11.7 & None \\
Yield stress MPa & None & $559(\mathrm{~A})$ \\
$B$ GPa & None & 2.201 \\
$t$ & None & 0.8 \\
$C$ & None & $2.1 \times 10^{-4}$ \\
Failure & Johnson-Holmquist & None \\
Hydro tensile limit $\mathrm{MPa}$ & 750 & None \\
\hline
\end{tabular}

\subsubsection{Construction of Simulation Model}

The calculations were conducted with the computer program AUTODYN from Century Dynamics. A snapshot of the initial construction of the simulation model is shown in Figure 3. A one-quarter 3D model with symmetric boundary conditions was built to reduce the calculation time. The abrasive 
particle was modeled in a spherical shape, which is different to those in the slurry, but is still useful for demonstrating the work of abrasive particles in the polishing process. Because SPH takes more time in searching for neighboring particles, the abrasive particle and the partial workpiece area around the impact site were built with SPH solver, while the remaining workpiece area was constructed using the Lagrange finite element mesh to improve the calculation efficiency. The smoothing length for the SPH particle was $80 \mathrm{~nm}$, and the finite element mesh size was $0.3 \mu \mathrm{m}$. In the ultrasonic process, the abrasive particles would be accelerated by the cavitation collapse force and the ultrasonic energy of the horn, which can create an initial velocity that the abrasive particle just touches the work surface ranging from several meters to several hundred meters per second [24,25]. Therefore, initial velocities of 1 , 20 , and $200 \mathrm{~m} / \mathrm{s}$ were applied to the abrasive particle along the $\mathrm{z}$ direction for a tentative comparison in this study, which is believed to be helpful in understanding the effect of abrasive particles on the surface smoothing process.

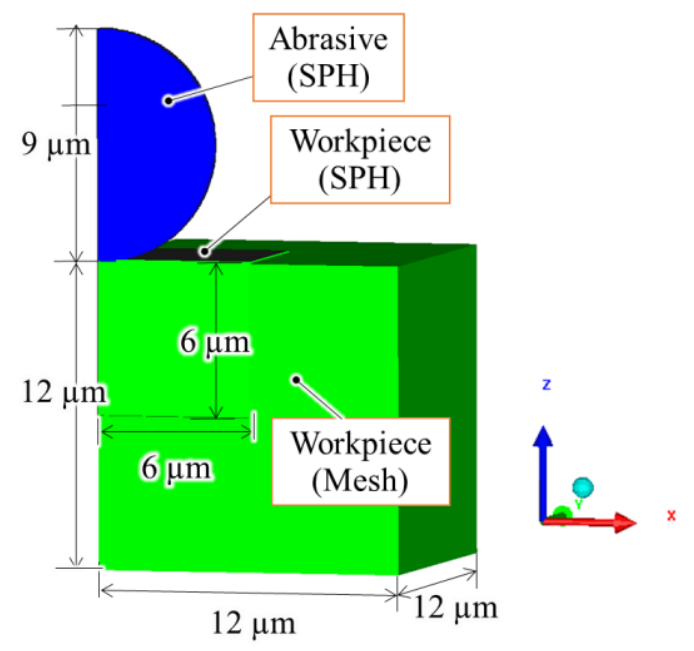

Figure 3. Snapshot of the initial construction of the simulation model.

\section{Results}

\subsection{Machined Surface Topography under Different Clearances between the Horn Tip and the Workpiece}

Figure 4 shows the SEM images of the surfaces machined with different clearances between the horn and the workpiece under an abrasive concentration of $10 \%$ before and after polishing for $5,10,20$, and $30 \mathrm{~min}$. For both cases, the original surfaces (at $0 \mathrm{~min}$ ) demonstrate the typical surface topography of metal-based AM parts which have numerous partially melted powders, larger agglomeration and balling structures, and step discontinuities due to the layer interface (Figure $4 a, b)$. All these contribute to a high initial Ra value of about $9.48 \mu \mathrm{m}$-measured before polishing. After 5 min of machining, we can notice that most of the partially melted powders were removed from their original sites, as shown in area A for both cases. The larger structures were also smoothed when the clearance was $1 \mathrm{~mm}$, as shown in area B of Figure 4a, while almost no change happened for $2 \mathrm{~mm}$ clearance (Figure $4 \mathrm{~b}$ ). With the increase in the machining time, almost all of the partially melted powders were removed for $1 \mathrm{~mm}$ clearance. Step discontinuities at the layer interface were also reduced. The roughness $\mathrm{Ra}$ was measured, which decreased to $2.93 \mu \mathrm{m}$ after $30 \mathrm{~min}$ of machining, and an obvious smoothing of the AM surface was obtained as shown in Figure 4a. However, it was found that the partially melted powders were predominately removed in the first $5 \mathrm{~min}$ for $2 \mathrm{~mm}$ clearance, and only slight material removal occurred in the remaining $25 \mathrm{~min}$. The larger structures and step discontinuities that remained on the surface after $30 \mathrm{~min}$ of machining were almost the same as the original ones. It is also noted that the removal process for the tightly attached, partially melted powder needs more time and leaves shallow pits on the machined surface, as shown in area $C$ for both cases. The results indicate that 
a clearance of $1 \mathrm{~mm}$ is appropriate for effective polishing. In addition, the clearance is sufficient to prevent the direct hammering of abrasive particles and extends the working life of the horn.
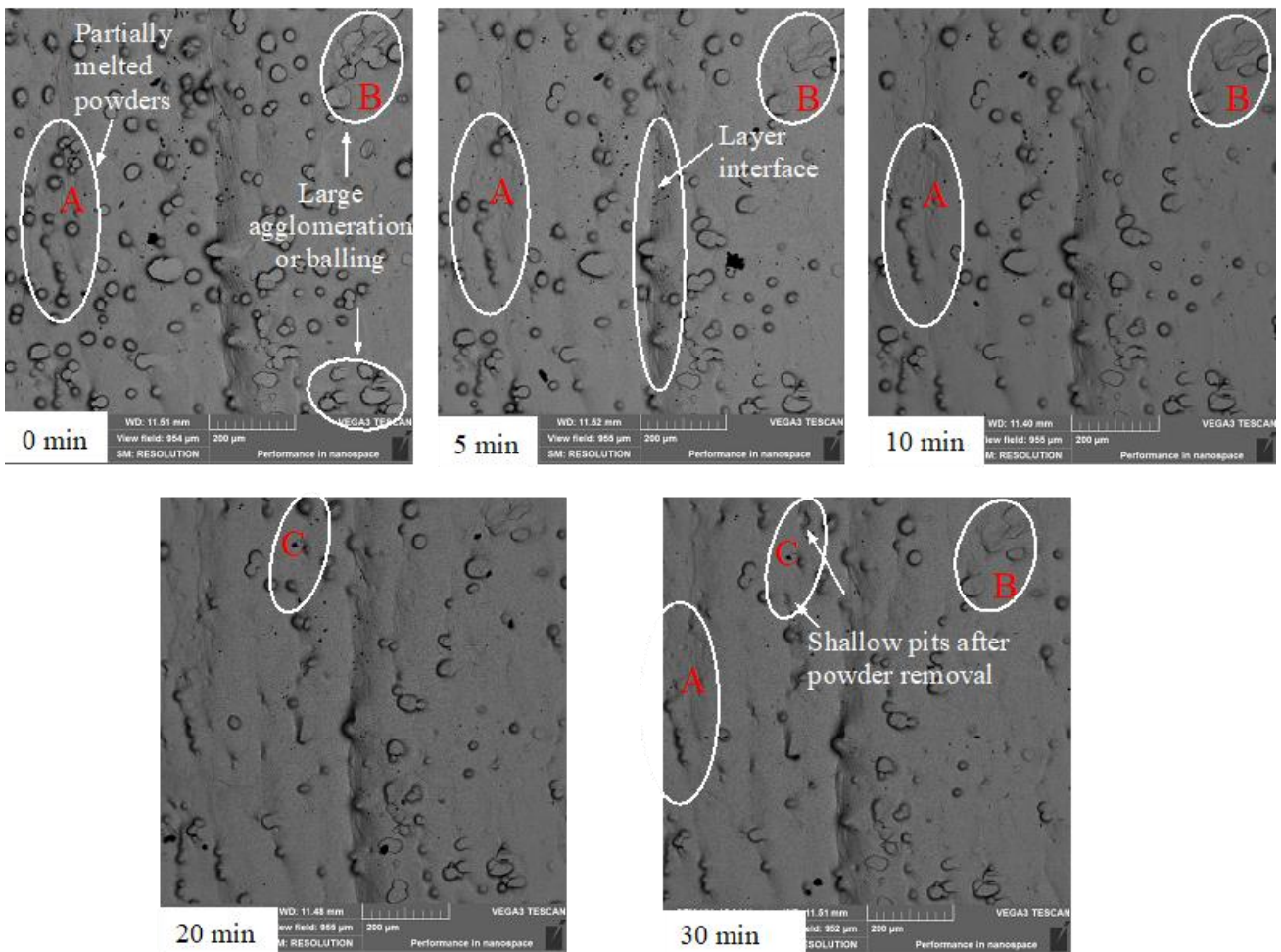

(a)
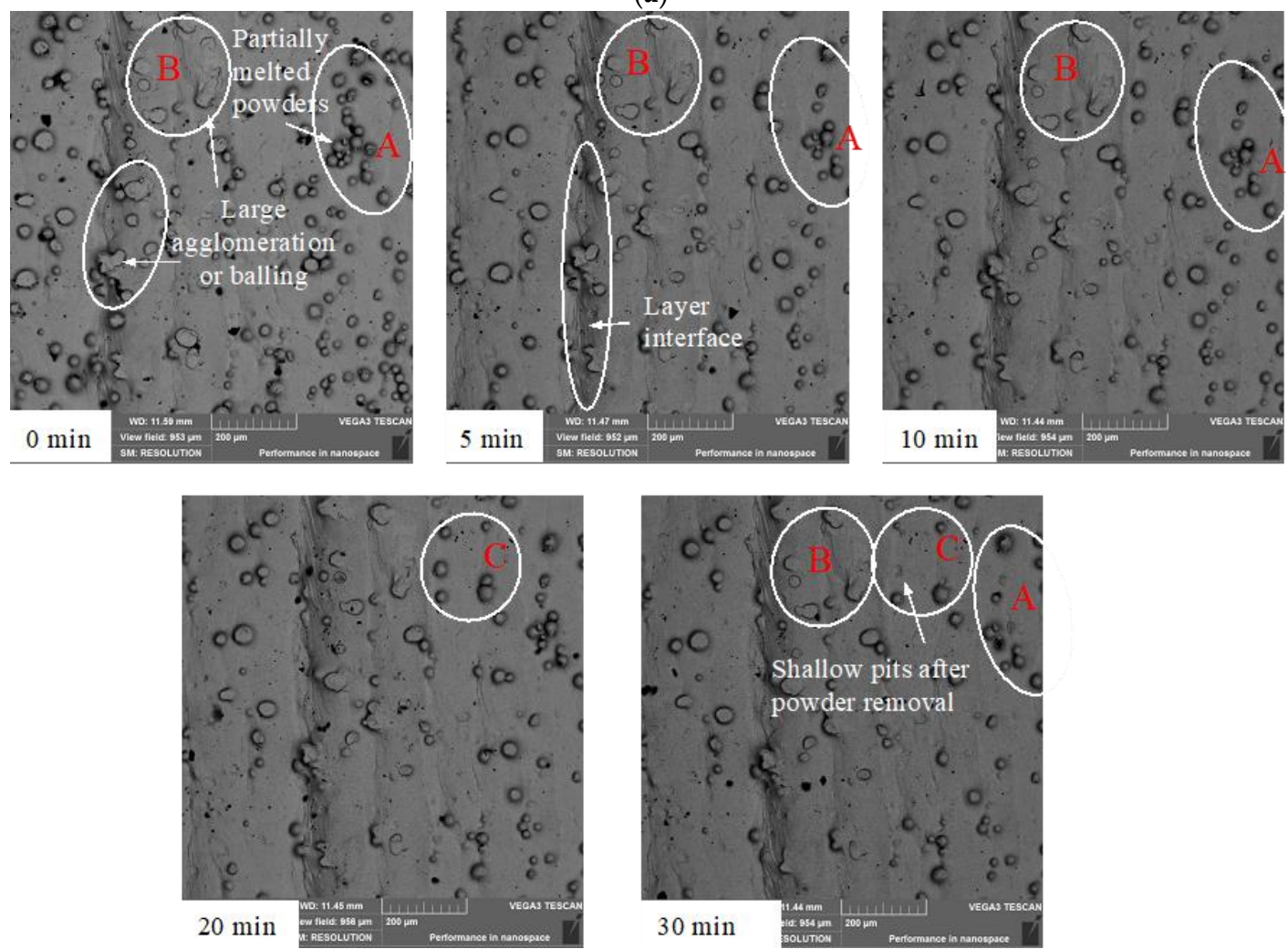

(b)

Figure 4. SEM images of the surfaces machined with different clearances between the horn and the workpiece under $10 \%$ abrasive concentration with the increase in polishing time: (a) $1 \mathrm{~mm}$; (b) $2 \mathrm{~mm}$. 


\subsection{Comprison Results of Ultrasonic Abrasive Polishing and Cavitation Collapse}

Figure 5 shows the SEM images of the surfaces after polishing with $10 \%$ and $0 \%$ abrasive concentration for $30 \mathrm{~min}$. Partially melted powders were removed, regardless of whether abrasive particles were added. However, it is obvious that the polishing result is better with addition of abrasive particles, because the larger structures and step discontinuities were also smoothed. The roughness Ra was decreased to $5.02 \mu \mathrm{m}$ after cavitation treatment alone, while it was decreased to $2.93 \mu \mathrm{m}$ upon adding abrasive particles. The difference in surface topography is further demonstrated in the comparison of 3D topographic maps, as shown in Figure 6.
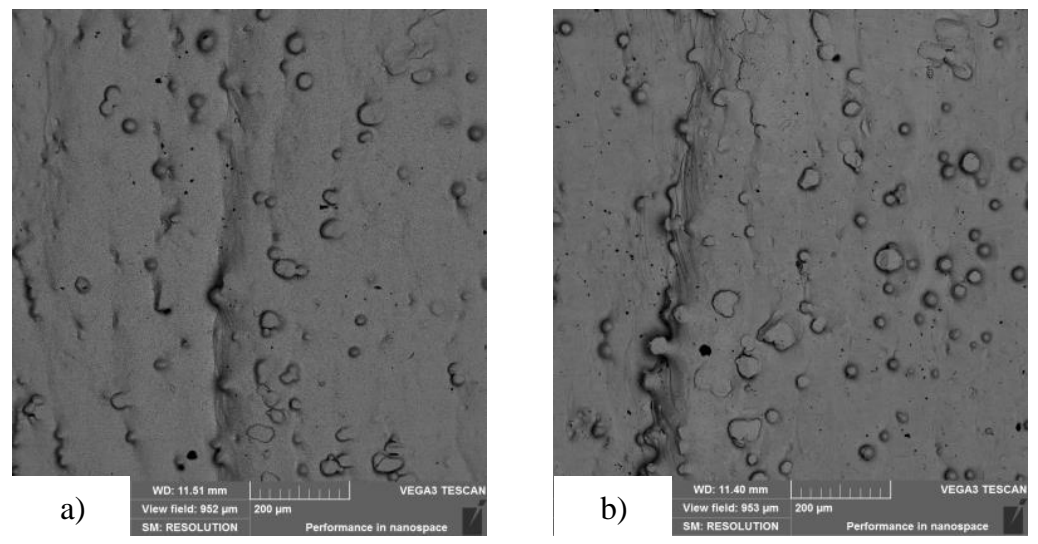

Figure 5. SEM images of the surfaces: (a) after polishing with $10 \%$ abrasive concentration for $30 \mathrm{~min}$ (same as Figure $4 a$ ); (b) after polishing with $0 \%$ abrasive concentration (cavitation only) for $30 \mathrm{~min}$.
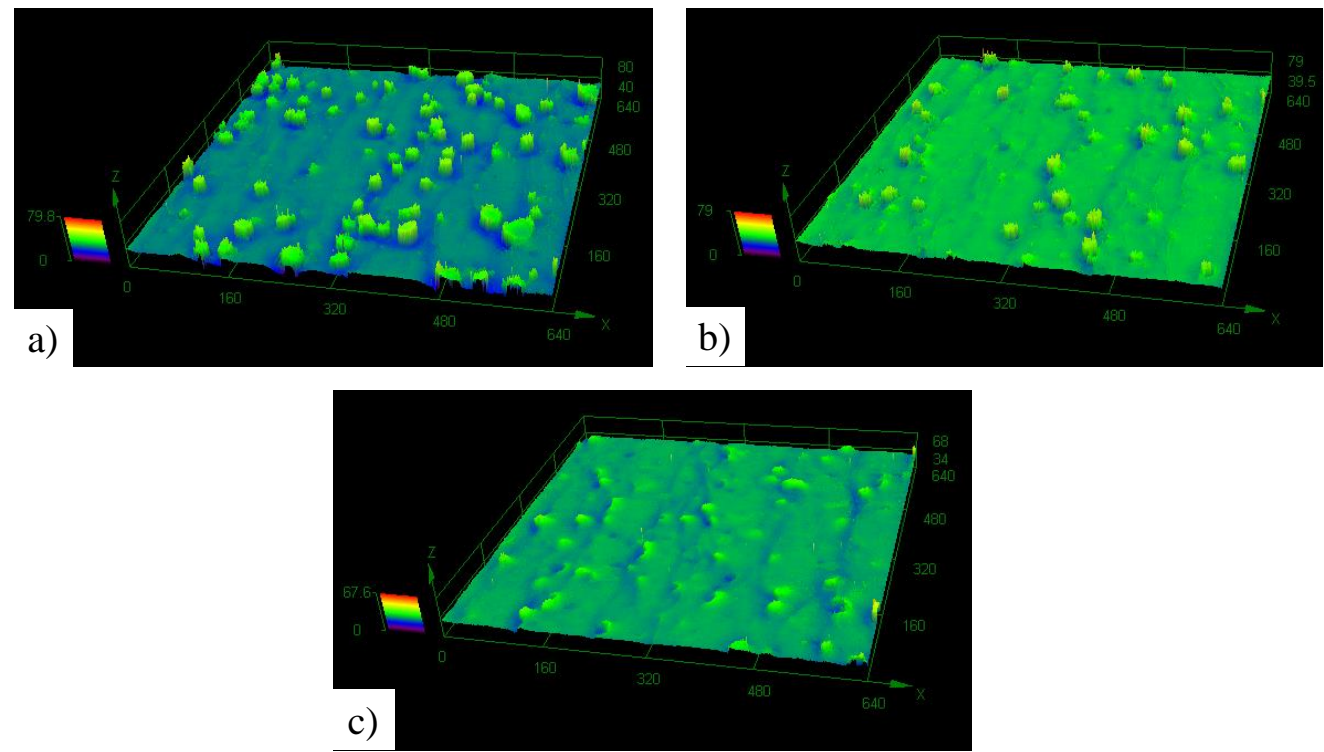

Figure 6. 3D topographic maps of: (a) as-manufactured AM workpiece surface; (b) surface after polishing with $0 \%$ abrasive concentration (cavitation only) for $30 \mathrm{~min}$; (c) surface after polishing with $10 \%$ abrasive concentration for $30 \mathrm{~min}$.

\subsection{Comparison Results for Different Ultrasonic Output Power}

Figure 7 shows laser microscope images of the surfaces polished with different ultrasonic output power under $10 \%$ abrasive concentration for $20 \mathrm{~min}$. An increase in the output power facilitates the removal of partially melted powders and large structures. The discontinuities at the interface were also largely smoothed at $600 \mathrm{~W}$. This is considered to be a result of the increase in the vibration 
amplitude, which will enhance the cavitation intensity and the impact velocity of micro-abrasive particles. Figure 8 illustrates the roughness Ra. The deviation of as-manufactured AM surface is high due to the partially melted powders and large structures. After ultrasonic abrasive polishing, some partially melted powders are removed and may leave micro-pits on the surface, so the deviation is still high. An improvement in surface finish can be obtained with an increase in the ultrasonic output power in this work.
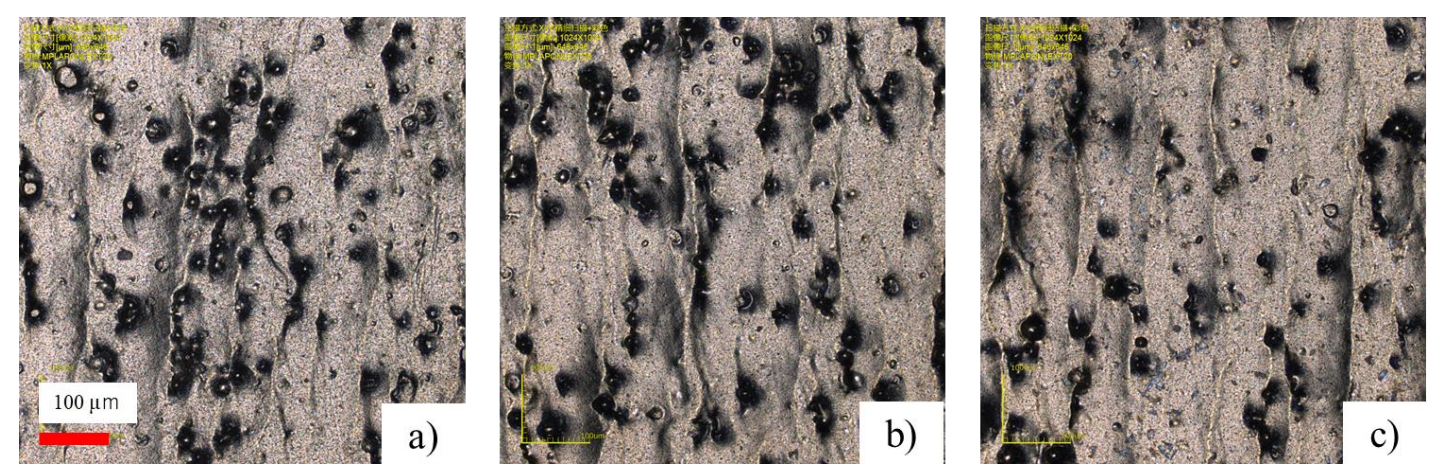

Figure 7. Laser microscope images of surfaces after polishing with $10 \%$ abrasive concentration for 20 min: (a) $400 \mathrm{~W}$; (b) $500 \mathrm{~W}$; (c) $600 \mathrm{~W}$.

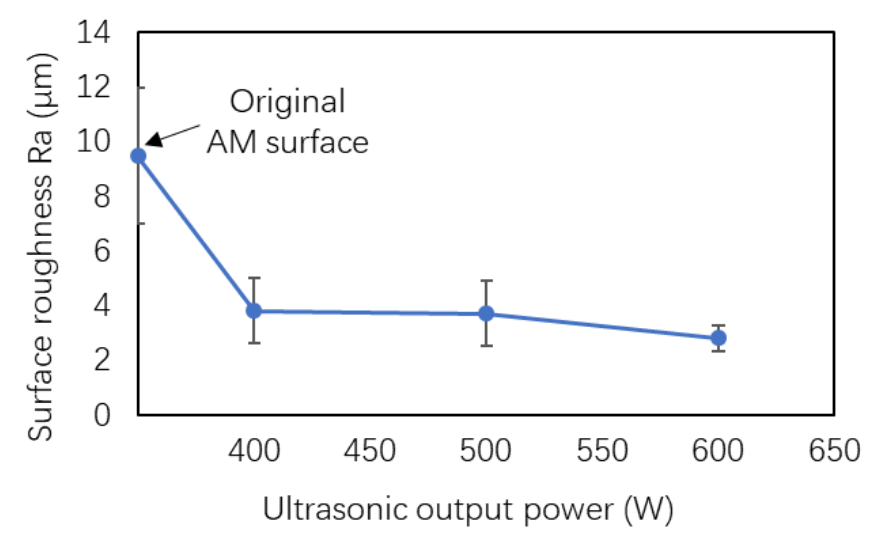

Figure 8. Roughness of specimens polished with different ultrasonic output power under abrasive concentration of $10 \%$ for $20 \mathrm{~min}$.

\subsection{Comprison Results for Different Abrasive Concentrations}

Figure 9 shows laser microscope images of the surfaces polished with different abrasive concentrations under $500 \mathrm{~W}$ for $20 \mathrm{~min}$. A decrease in partially melted powders can be confirmed with an increase in the abrasive concentration. Micro-sized abrasive particles suspended in the slurry act as bubble nucleation sites, which increase the overall cavitation intensity [26]. The total number of abrasive particles is larger for a higher concentration, hence they increase the material removal process through cavitation collapses and the abrasive particle effect. Figure 10 illustrates the roughness Ra for different abrasive concentrations. The average Ra value decreases with an increase in abrasive concentration of less than $30 \%$ and increases with concentration of $40 \%$. It is also noted that the standard deviation of $30 \%$ concentration is much larger than $20 \%$, which makes the roughness Ra fluctuate over a large range and results in a worse finish effect. The results indicate that the finish performance is generally improved with an increase in abrasive concentration in a certain range, however, a further increase cannot lead to a more desirable polishing effect. This is considered to be because a high abrasive concentration results in interference between the particles and a decentralization of the material removal, so that the polishing efficiency is weakened. 

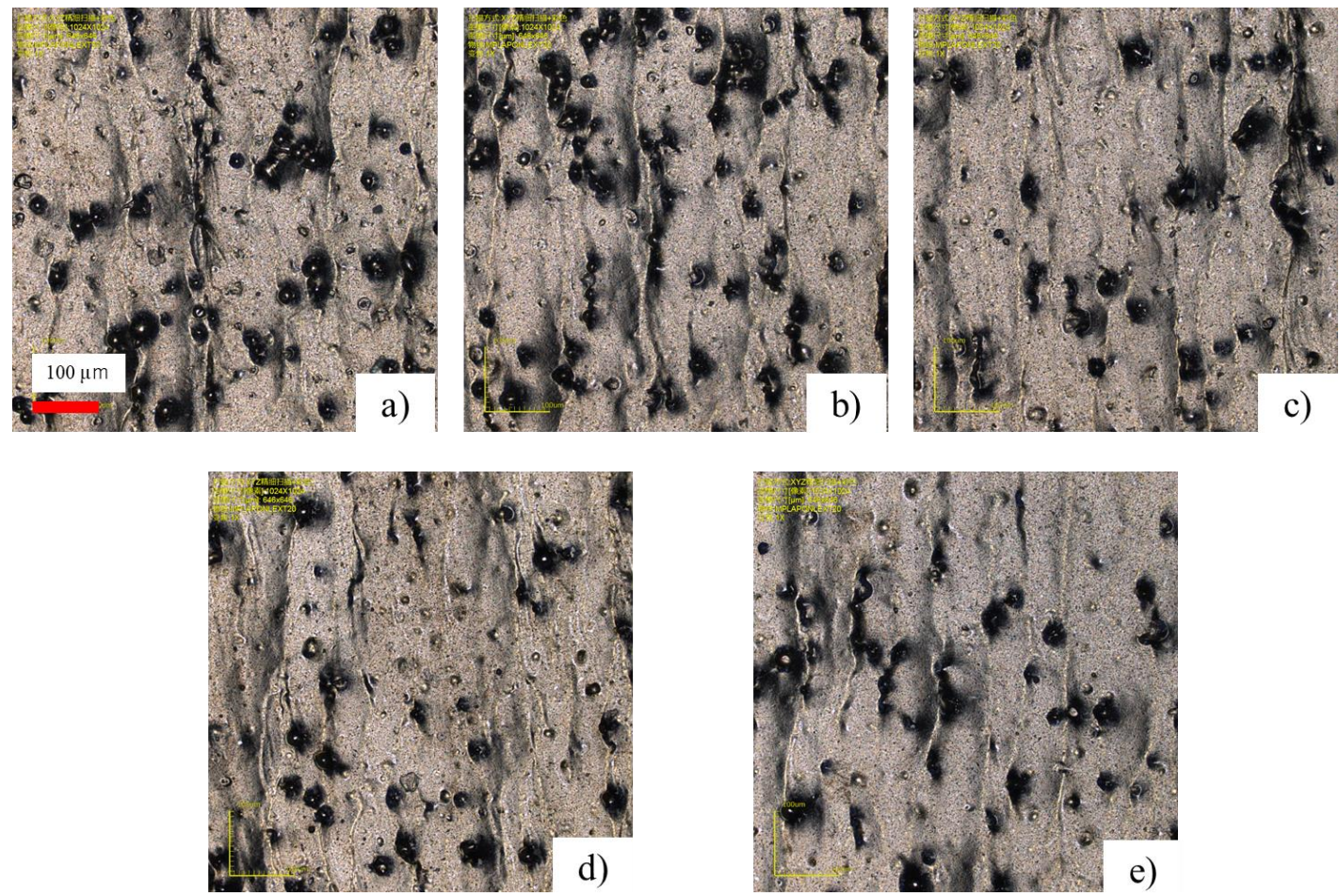

Figure 9. Laser microscope images of surfaces after polishing with $500 \mathrm{~W}$ for $20 \mathrm{~min}$ : (a) 5\%; (b) 10\%; (c) $20 \%$; (d) $30 \%$; (e) $40 \%$.

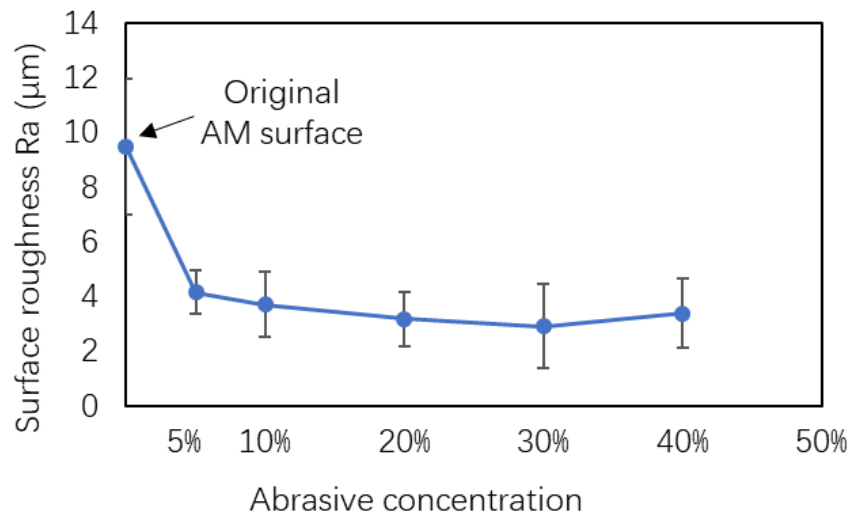

Figure 10. Roughness of specimens polished with different abrasive concentrations under $500 \mathrm{~W}$ for $20 \mathrm{~min}$.

\subsection{Simulation Results}

Figure 11 shows the time-dependent results of material status with different initial impact velocities along an $\mathrm{X}-\mathrm{Z}$ symmetric plane. The green, blue, and red elements indicate elastic, plastic and failure states, respectively. Figure 12 shows the comparison results after $20 \mathrm{~ns}$ calculation regarding the materials. For a slow velocity of $1 \mathrm{~m} / \mathrm{s}$, as shown in Figure 11a, the impact force of the abrasive particle is not large enough to make any changes in either abrasive or workpiece materials, and the particle just rebounded after impact. For a velocity of $20 \mathrm{~m} / \mathrm{s}$, a plastic region generated in the workpiece due to the abrasive impact after a calculation of $1 \mathrm{~ns}$. After impact, the fracture of the abrasive particle is confirmed, as shown in Figure 11b. When the velocity reached $200 \mathrm{~m} / \mathrm{s}$, the abrasive particle fractured during the impact, and a large plastic region occurred in the workpiece. After the particle left the work surface, a concave with a pile-up around the edge is confirmed, which can be well recognized in Figure 12. The results indicate that the impact velocity of the abrasive particle would have a large 
effect on surface smoothing. Because the impact velocity is determined by the cavitation collapse force and ultrasonic energy of the horn, the machining conditions, including the ultrasonic output power (vibration amplitude), abrasive concentration, and the clearance between the horn and workpiece, should be chosen carefully to improve the finishing effect.
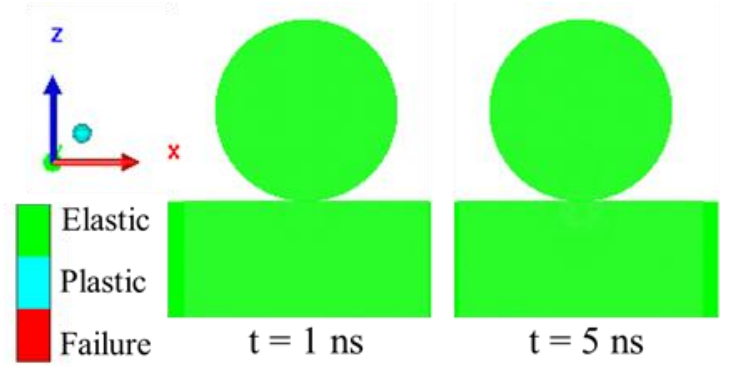

$\mathrm{t}=5 \mathrm{~ns}$

(a)
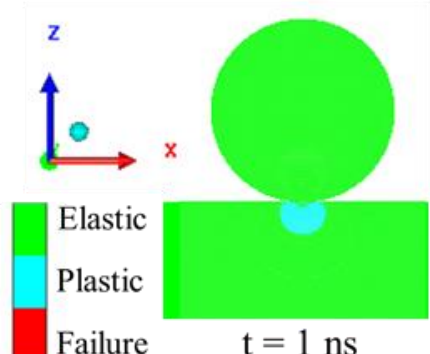

Failure
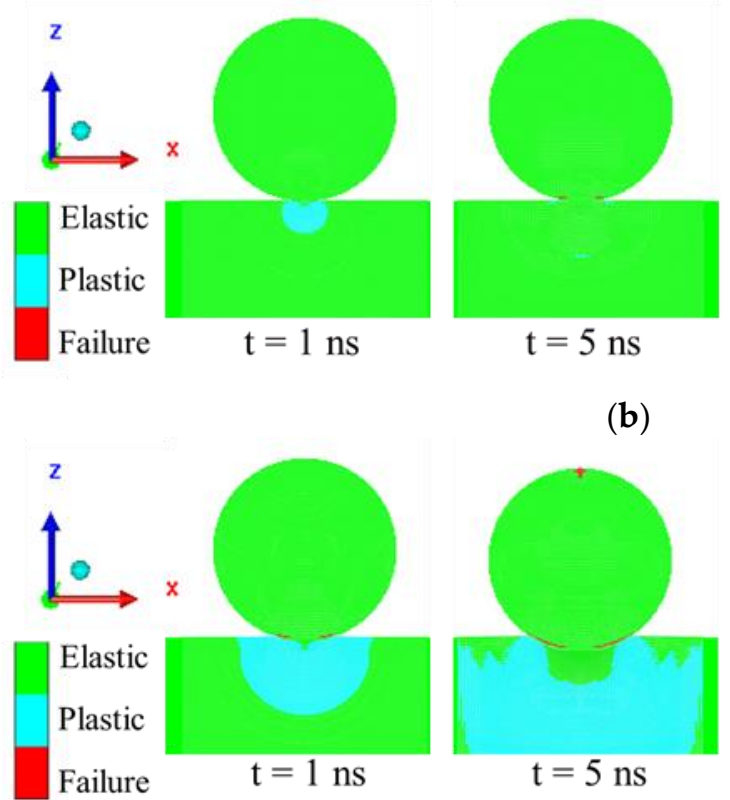

$\mathrm{t}=5 \mathrm{~ns}$

(b)

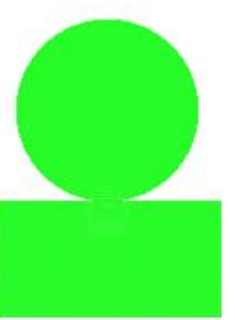

$\mathrm{t}=10 \mathrm{~ns}$

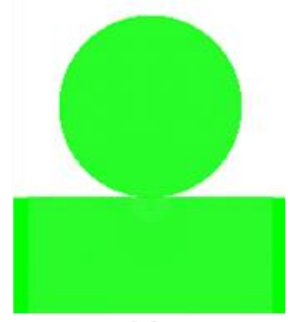

$\mathrm{t}=20 \mathrm{~ns}$

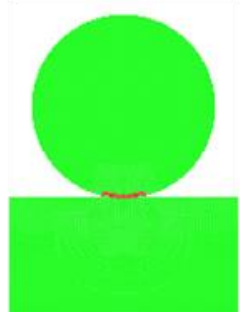

$\mathrm{t}=10 \mathrm{~ns}$

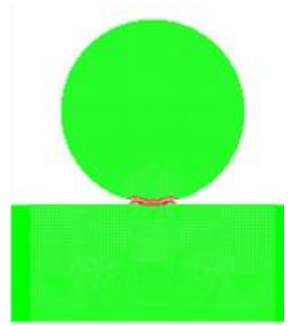

$\mathrm{t}=20 \mathrm{~ns}$
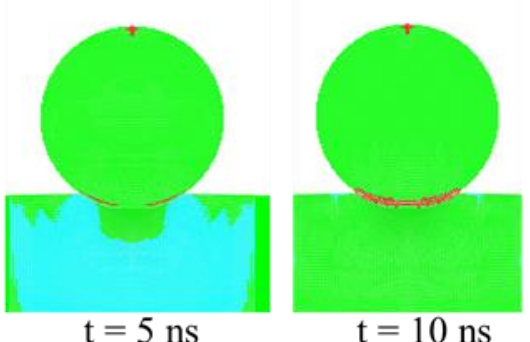

$\mathrm{t}=10 \mathrm{~ns}$

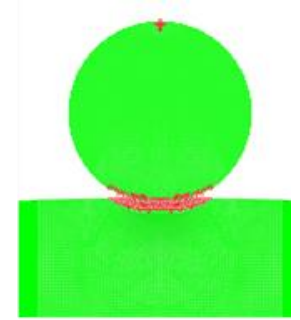

$\mathrm{t}=20 \mathrm{~ns}$

(c)

Figure 11. Time-dependent results of material status with different initial impact velocities: (a) 1 $\mathrm{m} / \mathrm{s}$; (b) $20 \mathrm{~m} / \mathrm{s}$; (c) $200 \mathrm{~m} / \mathrm{s}$ (green, blue, and red elements indicate elastic, plastic and failure states, respectively).

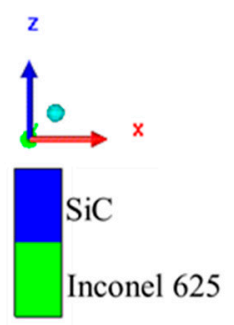

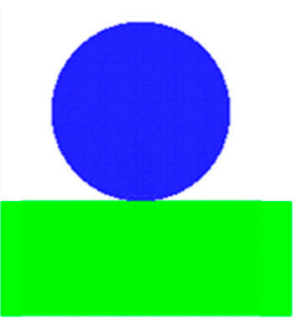

(a)

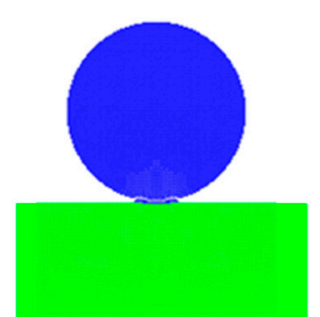

(b)

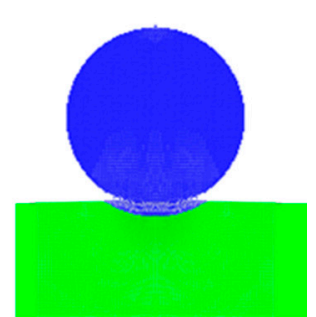

(c)

Figure 12. Comparison results of material distribution after $20 \mathrm{~ns}$ calculation with different initial impact velocities: (a) $1 \mathrm{~m} / \mathrm{s}$; (b) $20 \mathrm{~m} / \mathrm{s}$; (c) $200 \mathrm{~m} / \mathrm{s}$ (blue and green elements indicate $\mathrm{SiC}$ and Inconel 625 material, respectively). 


\section{Discussion}

Based on the results above, two material removal mechanisms can be considered responsible for the surface smoothing process during the ultrasonic abrasive polishing of additive manufactured components. The first is the material removal due to cavitation collapse pressure, which is effective in dislodging the partially melted powders from the surface. The bonding neck between a partially melted powder and the surface acts like a crevice, which entraps gas and improves the cavitation erosion [4]. The second material removal mechanism is based on the impact of abrasive particles suspended in the slurry. The abrasive particles are accelerated by the cavitation pressure and the ultrasonic energy of the horn, and tend to penetrate the workpiece in different directions. The SPH simulation in this study only demonstrated the vertical impact action of abrasive particles, which, it is believed, would smooth the surface by plastic deformation. However, it should be noted that the impact from other directions would result in material removal by micro-cutting or sliding [27]. All of these make abrasive particles capable of smoothing and further removing large structures and discontinuities on the surface of AM components. Figure 13 shows the schematic of material removal mechanisms in the ultrasonic abrasive polishing of additive manufactured components explained above.

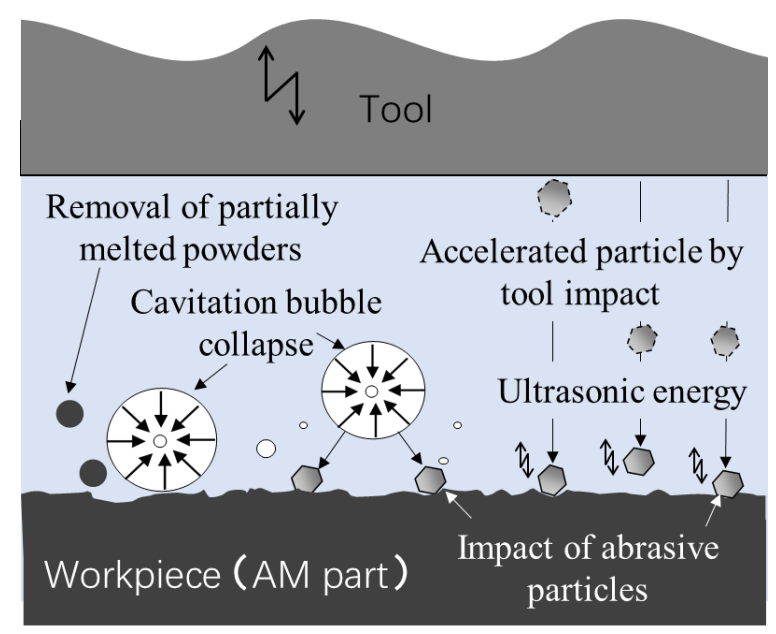

Figure 13. Material removal mechanism in the ultrasonic abrasive polishing of additive manufactured components.

The two material removal mechanisms are greatly influenced by the process conditions. Even though the general polishing performance under different conditions has been investigated through the experiments, the nature of the change is not fully understood. The real velocities of the abrasive particles accelerated by the cavitation collapse pressure and the ultrasonic energy of the horn should be further studied, so that the polishing process can be improved. In addition, the cavitation erosion is often associated with damage on smooth specimens based on earlier studies, so it may also have a tendency to worsen the surface smoothness in the polishing process. The control of the two conflicting effects of cavitation on AM surface finish is important to ensure efficient polishing, and should be investigated in the future study. It is believed that the technology could be an ideal solution for the surface modification of AM components. Moreover, as the ultrasonic abrasive polishing process is conducted uniformly on the whole working area by using suitable settings, this polishing method can be used to process surfaces with various complex shapes and internal features.

\section{Conclusions}

In this work, material removal in ultrasonic abrasive polishing was studied using both experiments and SPH simulations. The roles of cavitation bubble collapse and the impact of abrasive particles in material removal were confirmed. 
The following major conclusions have been drawn:

(1) Cavitation bubble collapse in ultrasonic polishing can efficiently remove the partially melted powders on additive manufactured surfaces, and a further improvement of surface quality can be obtained through the micro-cut and impact of abrasive particles in the slurry. In this work, the roughness was decreased to $2.93 \mu \mathrm{m}$ from the initial value of $9.48 \mu \mathrm{m}$ after $30 \mathrm{~min}$ of polishing.

(2) Increasing the output power enhances the cavitation intensity and the impact of abrasive particles, which would improve the polishing process.

(3) Micro-abrasive particles act as bubble nucleation sites, which increase the cavitation intensity and, accordingly, facilitate the material removal process. However, a high abrasive concentration will result in interference between the particles and a decentralization of material removal. Therefore, the polishing effect can be only improved when the abrasive concentration is within a certain range.

Author Contributions: Conceptualization, J.W.; Investigation, J.W., J.Z., and P.J.L.; Methodology, J.W. and J.Z.; Validation, J.W. and J.Z.; Writing—Original Draft Preparation, J.W.; Writing-Review \&Editing, J.W., P.J.L., and J.Z.

Funding: This research was funded by the National Natural Science Foundation of China [Grant no. 51805067], China Postdoctoral Science Foundation [Grant no. 2019M651093], Fundamental Research Funds for the Central Universities of China [Grant no. 3132019193].

Conflicts of Interest: The authors declare no conflict of interest.

\section{References}

1. Strano, G.; Hao, L.; Everson, R.M.; Evans, K.E. Surface roughness analysis, modelling and prediction in selective laser melting. J. Mater. Process. Technol. 2013, 213, 589-597. [CrossRef]

2. Gu, D.D.; Meiners, W.; Wissenbach, K.; Poprawe, R. Laser additive manufacturing of metallic components: Materials, processes and mechanisms. Int. Mater. Rev. 2012, 57, 133-164. [CrossRef]

3. Wycisk, E.; Solbach, A.; Siddique, S.; Herzog, D.; Walther, F.; Emmelmann, C. Effects of defects in laser additive manufactured Ti-6Al-4V on fatigue properties. Phys. Procedia 2014, 56, 371-378. [CrossRef]

4. Tan, K.L.; Yeo, S.H. Surface modification of additive manufactured components by ultrasonic cavitation abrasive finishing. Wear 2017, 378, 90-95. [CrossRef]

5. Kim, T.B.; Yue, S.; Zhang, Z.; Jones, E.; Jones, J.R.; Lee, P.D. Additive manufactured porous titanium structures: Through-process quantification of pore and strut networks. J. Mater. Process. Technol. 2014, 214, 2706-2715. [CrossRef]

6. Gordon, E.R.; Shokrani, A.; Flynn, J.M.; Goguelin, S.; Barclay, J.; Dhokia, V. A surface modification decision tree to influence design in additive manufacturing. In Proceedings of the International Conference on Sustainable Design and Manufacturing, Chania, Crete, Greece, 4-6 April 2016; Springer: Cham, Switzerland; pp. $423-434$.

7. Gao, H.; Li, S.; Fu, Y.; Wei, H.; Peng, C.; Wang, X. Abrasive flow machining of additively manufactured metal grilling parts. Acta Aeronaut. Astronaut. Sin. 2017, 38, 421210. (In Chinese)

8. Vaithilingam, J.; Goodridge, R.D.; Hague, R.J.; Christie, S.D.; Edmondson, S. The effect of laser remelting on the surface chemistry of Ti6al4V components fabricated by selective laser melting. J. Mater. Process. Technol. 2016, 232, 1-8. [CrossRef]

9. Lamikiz, A.; Sanchez, J.A.; de Lacalle, L.L.; Arana, J.L. Laser polishing of parts built up by selective laser sintering. Int. J. Mach. Tools Manuf. 2007, 47, 2040-2050. [CrossRef]

10. Łyczkowska, E.; Szymczyk, P.; Dybała, B.; Chlebus, E. Chemical polishing of scaffolds made of Ti-6Al-7Nb alloy by additive manufacturing. Arch. Civ. Mech. Eng. 2014, 14, 586-594. [CrossRef]

11. Pyka, G.; Burakowski, A.; Kerckhofs, G.; Moesen, M.; Van Bael, S.; Schrooten, J.; Wevers, M. Surface modification of Ti6Al4V open porous structures produced by additive manufacturing. Adv. Eng. Mater. 2012, 14, 363-370. [CrossRef]

12. Löber, L.; Flache, C.; Petters, R.; Kühn, U.; Eckert, J. Comparison of different post processing technologies for SLM generated 3161 steel parts. Rapid Prototyp. J. 2013, 19, 173-179. [CrossRef] 
13. Atzeni, E.; Barletta, M.; Calignano, F.; Iuliano, L.; Rubino, G.; Tagliaferri, V. Abrasive Fluidized Bed (AFB) finishing of AlSi10Mg substrates manufactured by direct metal laser sintering (DMLS). Addit. Manuf. 2016, 10, 15-23. [CrossRef]

14. Cheema, M.S.; Venkatesh, G.; Dvivedi, A.; Sharma, A.K. Developments in abrasive flow machining: A review on experimental investigations using abrasive flow machining variants and media. Proc. Inst. Mech. Eng. Part B 2012, 226, 1951-1962. [CrossRef]

15. Thoe, T.B.; Aspinwall, D.K.; Wise, M.L.H. Review on ultrasonic machining. Int. J. Mach. Tools Manuf. 1998, 38, 239-255. [CrossRef]

16. Komaraiah, M.; Reddy, P.N. A Study on the influence of workpiece properties in ultrasonic machining. Int. J. Mach. Tools Manuf. 1993, 33, 495-505. [CrossRef]

17. Baek, D.K.; Ko, T.J.; Yang, S.H. Enhancement of surface quality in ultrasonic machining of glass using a sacrificing coating. J. Mater. Process. Technol. 2013, 213, 553-559. [CrossRef]

18. Singh, R.; Khamba, J.S. Ultrasonic machining of titanium and its alloys: A review. J. Mater. Process. Technol. 2006, 173, 125-135. [CrossRef]

19. Hocheng, H.; Kuo, K.L. Fundamental study of ultrasonic polishing of mold steel. Int. J. Mach. Tools Manuf. 2002, 42, 7-13. [CrossRef]

20. ANSYS Inc. Autodyn: Theory Manual; Century Dynamics, a subsidiary of ANSYS Inc.: Canonsburg, PA, USA, 2005.

21. Holmquist, T.J.; Johnson, G.R. Response of silicon carbide to high velocity impact. J. Appl. Phys. 2002, 91, 5858-5866. [CrossRef]

22. ANSYS Workbench 19.0: Engineering Data Sources, Additive Manufacturing Materials. Available online: https://studentcommunity.ansys.com/thread/ansys-workbench-19-0-2/ (accessed on 8 December 2019).

23. Johnson, G.R.; Cook, W.H. A constitutive model and data for metals subjected to large strains, high strain rates and high temperatures. In Proceedings of the 7th International Symposium on Ballistics, Hague, The Netherlands, 19-21 April 1983; Volume 21, pp. 541-547.

24. Wang, J.; Shimada, K.; Mizutani, M.; Kuriyagawa, T. Effects of abrasive material and particle shape on machining performance in micro ultrasonic machining. Precis. Eng. 2018, 51, 373-387. [CrossRef]

25. Tzanakis, I.; Eskin, D.G.; Georgoulas, A.; Fytanidis, D.K. Incubation pit analysis and calculation of the hydrodynamic impact pressure from the implosion of an acoustic cavitation bubble. Ultrason. Sonochem. 2014, 21, 866-878. [CrossRef] [PubMed]

26. Haosheng, C.; Jiadao, W.; Darong, C. Cavitation damages on solid surfaces in suspensions containing spherical and irregular microparticles. Wear 2009, 266, 345-348. [CrossRef]

27. Ichida, Y.; Sato, R.; Morimoto, Y.; Kobayashi, K. Material removal mechanisms in non-contact ultrasonic abrasive machining. Wear 2005, 258, 107-114. [CrossRef] 